(2) Open Access Full Text Article

REVIEW

\title{
Assessment and management of nutrition in older people and its importance to health
}

This article was published in the following Dove Press journal:

Clinical Interventions in Aging

28 July 2010

Number of times this article has been viewed

\section{Tanvir Ahmed \\ Nadim Haboubi}

Adult and Elderly Medicine, Nevill Hall Hospital, Abergavenny, Wales, UK

Correspondence: Nadim Haboubi Consultant Physician. Adult and

Elderly Medicine, Nevill Hall Hospital, Abergavenny, NP7 7EG Wales UK

Tel +44 I873 732I58

Fax +44 I873732157

Email nadim.haboubi@wales.nhs.uk

\begin{abstract}
Nutrition is an important element of health in the older population and affects the aging process. The prevalence of malnutrition is increasing in this population and is associated with a decline in: functional status, impaired muscle function, decreased bone mass, immune dysfunction, anemia, reduced cognitive function, poor wound healing, delayed recovery from surgery, higher hospital readmission rates, and mortality. Older people often have reduced appetite and energy expenditure, which, coupled with a decline in biological and physiological functions such as reduced lean body mass, changes in cytokine and hormonal level, and changes in fluid electrolyte regulation, delay gastric emptying and diminish senses of smell and taste. In addition pathologic changes of aging such as chronic diseases and psychological illness all play a role in the complex etiology of malnutrition in older people. Nutritional assessment is important to identify and treat patients at risk, the Malnutrition Universal Screening Tool being commonly used in clinical practice. Management requires a holistic approach, and underlying causes such as chronic illness, depression, medication and social isolation must be treated. Patients with physical or cognitive impairment require special care and attention. Oral supplements or enteral feeding should be considered in patients at high risk or in patients unable to meet daily requirements.
\end{abstract}

Keywords: malnutrition, older people, anorexia of aging, sarcopinia, nutritional assessment

\section{Introduction}

Malnutrition is defined as a state in which a deficiency, excess or imbalance of energy, protein and other nutrients causes adverse effects on body form, function and clinical outcome. ${ }^{1}$ It is more common and increasing in the older population; currently $16 \%$ of those $>65$ years and $2 \%$ of those $>85$ years are classed as malnourished. ${ }^{2}$ These figures are predicted to rise dramatically in the next 30 years. Almost two-thirds of general and acute hospital beds are used by people aged $>65$ years. ${ }^{3}$ Studies in developed countries found that up to $15 \%$ of community-dwelling and home-bound elderly, $23 \%$ to $62 \%$ of hospitalized patients and up to $85 \%$ of nursing home residents suffer from malnutrition. ${ }^{4}$ Malnutrition is associated with a decline in functional status, impaired muscle function, decreased bone mass, immune dysfunction, anemia, reduced cognitive function, poor wound healing, delayed recovering from surgery, higher hospital and readmission rate, and mortality. ${ }^{5}$ The etiology is multifactoral and will be discussed at length under several headings:

- Biological changes of the digestive system with aging

- Physiological changes of the digestive system with aging

- Nutritional assessment in older people 
- Pathological and non-pathological weight loss in older people

- Nutrition

- Conclusion

\section{Biological changes of the digestive system}

There are age-related changes in the gastrointestinal tract. The difficulty is that with age it can be difficult to exclude pathological factors such as diabetes, pancreatitis, liver disease and malignancy, since these factors will have potential adverse effects on the intestine.

Selective neurodegeneration of the aging enteric nervous system can lead to gastrointestinal symptoms such as dysphagia, gastrointestinal reflux and constipation. ${ }^{6}$ Caloric reduction in rodents can prevent neuronal loss, suggesting that diet may influence the aging gut. ${ }^{7}$ Esophageal motility may reduce the reduction of neurons in the mesenteric plexus in older people. ${ }^{8}$ Gastric motility is impaired with aging ${ }^{9}$ but the small intestine is unaffected. ${ }^{10}$ With age colonic motility can be influenced by signal transduction pathways and cellular mechanisms that control smooth muscle contraction which could lead to constipation. ${ }^{11}$

Reduced gastric acid secretions have an increasing prevalence with aging. Hypochlorhydia occurs due to chronic gastritis. Consequently, proton pump inhibitors are frequently used for prolonged periods in older people leading to suppressed acid secretions. Procedures such as vagotomy and gastric resections (both seen in older people) cause reduced acid levels. The overall reduction in acid secretions predisposes the gut to small bowel bacterial overgrowth. ${ }^{12}$ One study highlighted that $71 \%$ of patients on a geriatric ward had bacterial overgrowth of the small intestine and $11 \%$ were found to be malnourished..$^{13}$ Bacterial overgrowth has been proven to be associated with reduced body weight and reduced intake of micronutrients. ${ }^{14}$

Structural changes of the pancreas are seen with aging, but no functional age-related changes are seen with the fluorescein dilaurate test. ${ }^{15}$ Secretagogue-stimulated lipase, chymotrypsin and bicarbonate concentration in pancreatic juice have all been shown to decline with aging. ${ }^{16}$ Other studies found little evidence of reduced pancreatic secretion with age-independent of factors such as disease and drugs. ${ }^{17}$ The liver declines in size and blood flow with age but microscopic changes are subtle. ${ }^{18}$ In mice with age it has been shown that changes in the expression of genes in the liver are involved in inflammation, cellular stress and fibrosis. ${ }^{19}$ Caloric restriction in mice appeared to reverse age-related changes, indicating that diet influences age-related changes. ${ }^{20}$ Changes can occur in the small intestine such as decline in the number of villi and crypts, ${ }^{18}$ loss of villi and enterocyte height ${ }^{21}$ and decline in mucosal surface. ${ }^{22}$ However,
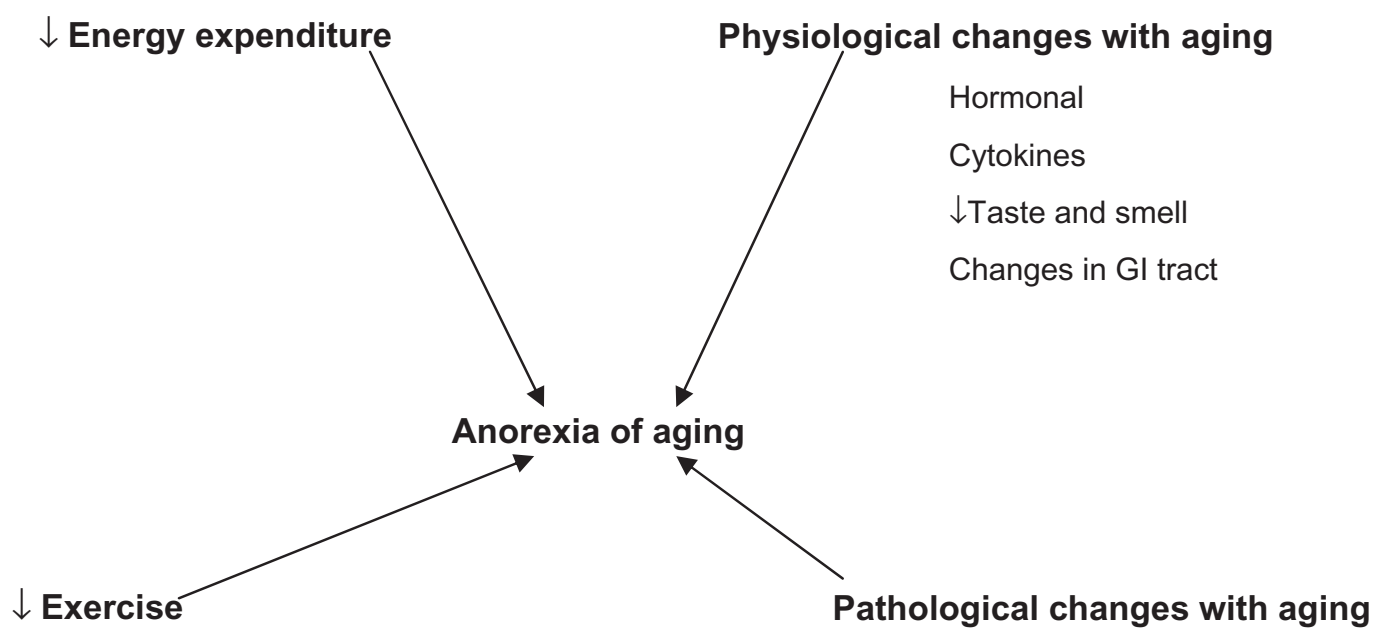

Medical

Drugs

Psychological

Social

Figure I A depiction of the "anorexia of aging".

Abbreviation: $\mathrm{Gl}$, gastrointestinal. 
there is no clear association between intestinal morphology and nutrient uptake with aging. ${ }^{23}$

\section{Physiological changes of digestive system and aging \\ The anorexia of aging}

With increasing age appetite declines and food consumption declines. Healthy older people are less hungry and are fuller before meals, consume smaller meals, eat more slowly, have fewer snacks between meals and become satiated after meals more rapidly after eating a standard meal than younger people. The average daily intake of food decreases by up to $30 \%$ between 20 and 80 years. ${ }^{24}$ Most of the age-related decrease in energy is a response to the decline in energy expenditure with age. However in many older people the decrease in energy intake is greater than the decrease in energy expenditure, and therefore body weight is lost. This physiological age-related reduction in appetite and energy intake has been termed the "anorexia of aging" (Figure 1). ${ }^{4}$

\section{Changes in body weight and body composition}

Cross-sectional studies have shown that body weight and body mass index (BMI) increase with age until approximately 50 to 60 years, after which they both decline. ${ }^{25}$ A 2-year prospective study showed that community-dwelling American men aged $>65$ years lost an average of $0.5 \%$ of their body weight per year and $13.1 \%$ of the group had a weight loss of $4 \%$ per year. ${ }^{26}$ A prospective cardiovascular health study looked at 4714 home-dwelling subjects $>65$ years who did not have cancer. ${ }^{27}$ In the 3 years after the study entry $17 \%$ had lost $5 \%$ or more of their initial body weight. This group were shown to have increased risk-adjusted mortality over the next 4 years compared to the group with stable weight. There is a $\mathrm{J}$ shaped curve association with mortality and body weight with increased mortality with low and high BMIs. ${ }^{28}$ At a BMI $<22$ there is a steady increase in mortality and the combined effect of being underweight and increasing age has a deleterious effect on mortality. ${ }^{29}$

With age, body fat increases and fat-free mass decreases because of loss of skeletal muscle, with a loss of up to $3 \mathrm{~kg}$ of lean body mass per decade after the age of 50 . The mean body fat of a 20 -year-old man weighing $80 \mathrm{~kg}$ is $15 \%$ compared to $29 \%$ in 75 -year-old man of the same weight. ${ }^{30}$ The cause of increase fat is multifactoral: reduced physical activity, reduced growth hormone secretion, diminished sex hormones and decreased resting metabolic rate. The distribution of fat in older people is different from that of younger people. A greater proportion of body fat is intra-hepatic and intra-abdominal, which is associated with insulin resistance ${ }^{31}$ and higher risk of ischemic heart disease, stroke and diabetes.

\section{Etiology of weight loss}

Three distinct mechanisms of weight loss in older people have been identified ${ }^{32}$

- Wasting

- Cachexia

- Sarcopenia

Wasting, an involuntary loss of weight, is mainly due to poor dietary food intake which can be caused by disease and psychological factor causing an overall negative energy balance.

Cachexia is an involuntary loss of fat-free mass (muscle, organ, tissue, skin and bone) or body cell mass; it is caused by catabolism and results in changes in body consumption. An acute immune response occurs. Cytokines are released (interleukin [IL]-1, IL-6, tumor necrosis factor alfa [TNF $\alpha]$ ) that have profound effects on hormone production and metabolism causing increased resting energy expenditure. ${ }^{33}$ Amino acids from muscle to the liver, an increase in gluconeogenesis and a shift of albumin production to acute phase proteins causes nitrogen balance to become negative, so muscle mass is lost. Cachexia is seen in many chronic diseases such as heart failure and rheumatoid arthritis. It is also seen in malignancy.

The major age-related physiological change in older people is a decline in skeletal muscle mass, known as sarcopenia. ${ }^{34}$ Reduced physical activity has a crucial role since lack of exercise causes muscle disease and, with time, muscle loss. However, lack of exercise is not the only cause and it is thought that hormonal, neural and cytokine activities play a role. ${ }^{32}$ Increased cytokine activity increases levels of acute phase proteins which break down muscle. Levels of sex hormones, glucocorticoids and catecholamines decline in older people which in turn increase pro-inflammatory cytokines. The central nervous system can play a part in sarcopenia. Neurones lost from the spinal cord will lead to loss of muscle. ${ }^{35}$ Also the remaining neurones adopt muscle fibers and control larger units of muscle cells causing the units to become less efficient, which leads to weakness. Stroke and neural disease cause neurone cell death and result in muscle atrophy.

\section{Physiological anorexia}

Causes of physiological anorexia are not fully understood, but the following are thought to contribute:

- Diminished sense of smell and taste 
- Increased cytokine activity

- Delayed gastric emptying

- Altered gastric distension

- Hormonal

Taste and smell make food enjoyable. The sense of taste and smell deteriorate with age. In one study more than $60 \%$ of subjects 65 to 80 years and more than $80 \%$ of subjects aged $>80$ years had developed a reduced sense of smell and taste compared to less than $10 \%$ of those $<50$ years old. ${ }^{36}$ The decline in sense of smell decreases food intake in older people and can influence the type of food eaten, and it has been shown that a reduced sense of smell is associated with reduced interest in and intake of food. Also, older patients with a reduced sense of taste tend to have a less varied diet and consequently develop micronutrient deficiencies. The loss of sense of taste is not understood fully but may be caused by a reduced number of taste buds. ${ }^{37}$ Modifications in the olfactory epithelium, receptors and neural pathways may affect sense of smell. Drugs such as Parkinson's medications and antidepressants affect sense of taste. Studies have shown that improving flavor of foods can improve nutritional intake and body weight in nursing-home patients. ${ }^{38}$

The role of cytokines has been discussed earlier. Circulating levels of IL1, IL6 and TNF $\alpha$ have been shown to be higher in older people and associated with reduced muscle mass.

Older people commonly complain of increased fullness and early satiation during a meal which may be caused by changes in gastrointestinal sensory function, as with age there is reduced sensitivity to gastrointestinal distension. Aging is associated with impairment of receptive relaxation of the gastric fundus, causing rapid antral filling and distension and earlier satiety. ${ }^{39}$

In a study in which young and old men were underfed by approximately $750 \mathrm{kcal} /$ day for 21 days, both groups of men lost weight. ${ }^{40}$ After the underfeeding period the men were allowed to eat freely. The young men ate more than at baseline and quickly returned to their normal weight, whereas the older men did not compensate and returned to their baseline intake and did not regain weight. The combination of age-related physiological anorexia and impaired homeostasis means older people do not respond to acute undernutrition compared with young men.

The hypothalamus controls hunger and satiety. The nucleus arcuatus has neurones that release neuropeptide $Y$ (NPY), an agouti-related peptide, which mediates hunger and inhibit satiety. ${ }^{41}$ Pro-opiomelacortin, which is produced in the nucleus arcuatus, stimulates satiety. ${ }^{41}$ Peripheral hormones affect the hypothalamus hunger-satiety control regulation.
Cholecystokinin (CCK) is released in the proximal bowel and is the protype satiety hormone. It is released in the response to nutrients from the antrum, particularly lipids and proteins. ${ }^{42}$ It has been shown to be increased in older people and correlated with high levels of satiety and low hunger. ${ }^{43}$ Pancreatic polypeptide (PPY) is released by the distal intestine in the presence of nutrients in the lumen. ${ }^{44}$ PPY inhibits NPY and causes satiety. Both CCK and PPY are enteric peptides involved in gastrointestinal motility in response to eating. ${ }^{45}$ High levels of fasting and postprandial CCK and PPY may cause prolonged satiety by slowing antral emptying.

Leptin is a hormone produced by adipose cells whose main role is maintaining energy balance. Low leptin signals loss of body fat and a need for energy intake, while high leptin level implies adequate body fat and no need for further food intake. ${ }^{41}$ Older people tend to have higher levels of leptin. ${ }^{46}$

Insulin regulates glucose metabolism. It is a satiety hormone that works by enhancing the leptin signal to the hypothalamus and inhibiting gherlin, the only peripheral hormone known to stimulate appetite. ${ }^{47}$ It is produced and secreted in the endocrine mucosa to enhance food intake. Aging is associated with reduced glucose tolerance and elevated insulin levels, which may amplify the leptin signal ${ }^{48}$ and inhibit ghrelin. ${ }^{49}$

\section{Nutritional assessment Dietary assessment}

Quantifying nutritional intake is best preformed by a dietitian. Different methods can be used. Twenty-four hour recall is commonly used and is based on an interview during which the patient recalls all food consumed in the previous 24 hours. ${ }^{50}$ The main disadvantages are that it represents only food intake for 1 day and may not represent a patient's typical intake. Data can also be affected if the patient has cognitive impairment. Food records for 7 days for all food and drink consumed can be used and help eliminate day-to-day variations. A food frequency multiquestion questionnaire is used to explore dietary intake over a period of time. ${ }^{51}$ This is more suitable for evaluation of groups rather than individuals. Unintentional weight loss is one of the best predictors of worst clinical outcome and in older people is associated with significant morbidity and mortality. ${ }^{52}$

\section{Clinical assessment}

A large number of clinical signs indicate nutritional deficiencies. The general impression is a wasted, thin individual with dry scaly skin and poor wound healing. The hair is thin and nails are spooned and depigmented. Patients complain of bone and joint pain and edema. Specific nutritional deficiencies are associated with specific clinical signs (see Table 1). 
Table I Clinical signs and nutritional deficiencies

\begin{tabular}{|c|c|c|}
\hline System & Sign or symptom & Nutrient deficiency \\
\hline \multirow[t]{7}{*}{ Skin } & Dry scaly skin & Zinc/essential fatty acids \\
\hline & Follicular hyperkeratosis & Vitamin A, C \\
\hline & Petechiae & Vitamin C, K \\
\hline & Photosensitive & Niacin \\
\hline & dermatitis & \\
\hline & Poor wound healing & Zinc, vitamin C \\
\hline & Scrotal dermatitis & Riboflavin \\
\hline \multirow[t]{2}{*}{ Hair } & Thin/depigmented & Protein \\
\hline & Easy pluckability & Protein, zinc \\
\hline \multirow[t]{3}{*}{ Nail } & Transverse & Albumin \\
\hline & depigmentation & \\
\hline & Spooned & Iron \\
\hline \multirow[t]{4}{*}{ Eyes } & Night blindness & Vitamin $A$, zinc \\
\hline & Conjunctival & Riboflavin \\
\hline & inflammation & \\
\hline & Keratomalacia & Vitamin A \\
\hline \multirow[t]{4}{*}{ Mouth } & Bleeding gums & Vitamin C, riboflavin \\
\hline & Glositis & Niacin, piridoxin, riboflavin \\
\hline & Atrophic papillae & Iron \\
\hline & Hypogeusia & Zinc, vitamin A \\
\hline \multirow[t]{2}{*}{ Neck } & Thyroid enlargement & lodine \\
\hline & Parotid enlargement & Protein \\
\hline \multirow[t]{2}{*}{ Abdomen } & Diarrhea & Niacin, folate, vitamin $\mathrm{BI} 2$ \\
\hline & Hepatomegaly & Protein \\
\hline \multirow[t]{5}{*}{ Extremities } & Bone tenderness & Vitamin D \\
\hline & Joint pain & Vitamin C \\
\hline & Muscle tenderness & Thiamine \\
\hline & Muscle wasting & Protein, selenium vitamin $\mathrm{D}$ \\
\hline & Edema & Protein \\
\hline \multirow[t]{6}{*}{ Neurological } & Ataxia & Vitamin $B 12$ \\
\hline & Tetany & Calcium, magnesium \\
\hline & Parasthesia & Thiamine, vitamin $\mathrm{B} / 2$ \\
\hline & Ataxia & Vitamin BI2 \\
\hline & Dementia & Vitamin $\mathrm{B} \mid 2$, niacin \\
\hline & Hyporeflexia & Thiamine \\
\hline
\end{tabular}

\section{Screening tools}

The Malnutrition Universal Screening Tool (MUST) is a five-step screening tool to identify adults who are malnourished or at risk of malnutrition. ${ }^{53}$ It includes management guidelines that can be used to develop a care plan. The tool is being used both in hospitals and in the community. The tool is easy to use and can be used by all care workers to derive a malnutrition risk score of either low, medium or high. It consists of three components: BMI, history of unexplained weight loss, and acute illness effect. Studies have shown that it has a high predictive validity in the hospital environment (length of stay, mortality in older people, and discharge destination in orthopedic patients) ${ }^{54}$ It is more efficient and faster than most other screening tools (3 to 5 minutes)..$^{55}$ It has been recommended as a screening tool by the National Institute of Clinical Excellence (NICE), the British Association for Parental and Enteral and Nutrition (BAPEN) and the British Dietitian Association (BDA).
The Mini Assessment (MNA) and Malnutrition Risk Scale (SCALES) were specifically designed for older patients. The MNA test consists of 18 items and takes less than 15 minutes to perform. It has been shown to predict morbidity and mortality in a study of an elderly Danish population..$^{56}$ The SCALES (S-sadness C-Cholesterol A-Albumin L-Loss of weight E-Eating problem physical/cognitive S-Shopping problems) test was designed for outpatient screening. The subjective global assessment relies on physical signs of undernutrition and patient history and does not use laboratory findings. It is simple to use, quick (takes a few minutes) and has been shown to be reliable in elderly outpatients. ${ }^{57}$

\section{Anthropometric assessment}

The Quetelet index relates weight $(\mathrm{kg})$ to the square of the height $\left(\mathrm{m}^{2}\right)$, which enables calculation of body mass index (BMI) ${ }^{58}$ It predicts disease risk in those termed underweight and in those who are obese. The World Health Organization categorizes underweight as BMI $<18.5$, normal 18.5 to 24.9, overweight 25 to 29.9 and obese 30 to 39.9 , and extreme obesity $>40 .{ }^{59}$ The further a patient moves outside the normal reference range the more the association with morbidity and mortality increases. ${ }^{60}$ Measurement of BMI in older people has certain limits such as loss of height caused by vertebral collapse, change in posture and loss of muscle tone. In these cases height should be obtained from certain body segments, such as leg, arm and arm span. ${ }^{61}$ BMI can be unreliable in the presence of confounding factors such as ascites and edema. In addition it does not identify unintentional weight loss as a single assessment.

Skinfold measurement using tricipital skinfold is particularly important together with arm circumference, and can be used to calculate muscular circumference of the arm, which indicates lean mass. ${ }^{62}$ Mid-upper arm circumference is a helpful indicator of malnutrition in ill patients (normal $23 \mathrm{~cm}$ in males, $>22 \mathrm{~cm}$ females). This measurement has been shown to be an independent predictor of mortality in older people in long-term institution. ${ }^{63} \mathrm{~A}$ formula (Haboubi-Kennedy) has been devised using both BMI and mid-arm circumference to evaluate nutritional status. ${ }^{64}$

Biometric impedance analysis is a simple, non-invasive and inexpensive method to estimate total body water, extracellular water, fat-free mass and body cell mass. It is a measurement of the resistance that the body provides against the passing of an electric current. Several studies have demonstrated that low body cell mass has a prognostic value in malnourished patients. ${ }^{65}$ Using anthropometric data a study tried to obtain reference values for various body compartments. However the 
upper age group in the study was 64, and therefore at present there are a lack of data in older age groups. ${ }^{66}$

\section{Biochemical markers}

Serum proteins synthesized by the liver have been used as markers of nutrition albumin, transferrin, retinol-binding proteins and thyroxine-binding prealbumin. ${ }^{67}$ Serum albumin is the most commonly used marker since it can predict mortality in older people. However albumin can be affected by not only nutritional state but by other factors, including inflammation and infection. This limits their usefulness especially in acutely unwell patients. Albumin has a long half-life and therefore is not useful for looking at short-term changes in protein and energy intake. ${ }^{68}$ Transferrin is a more sensitive marker of early protein-energy malnutrition but is affected by a number of conditions including pregnancy, iron deficiency, hypoxia, chronic infection and hepatic disease. ${ }^{68}$ Malnutrition impairs the immune system and decreases lymphocyte proliferation. ${ }^{69}$ Low total serum cholesterol has been associated with increased risk of malnutrition. ${ }^{70}$ Assessment of vitamins and trace elements is also important since deficiencies can lead to medical complications. To date there is no single biochemical marker of malnutrition as a screening test. The main value of biochemical markers is in a detailed assessment and monitoring.

\section{Pathological and non-pathological causes of weight loss}

Pathological factors become more common with age and most causes are treatable. This treatment can be medical, social or psychological.

\section{Medical}

- Cardiac eg, chronic heart failure

- Respiratory disease, eg, chronic obstructive pulmonary disease

- Gastrointestinal, eg, malabsorption syndromes, dysphagia, Helicobacter pylori, atrophic gastritis

- Endocrine disorders, eg, diabetes thyrotoxicosis

- Neurological, eg, stroke, Parkinson's disease, motor neurone disease

- Infection, eg, pneumonia, urinary tract infection

- Malignancy

- Physical disability, eg, arthritis

- Alcoholism

- Poor dentition

- Drugs (see Table 2)

\section{Psychological}

- Delirium
Table 2 Drugs that may cause anorexia in older people

\begin{tabular}{ll}
\hline System & Drug \\
\hline Cardiovascular & Amiodorone, frusemide, digoxin, \\
& spironolcatone \\
Neurological & Levodopa, fluoxetine, lithium \\
Gastrointestinal & $\mathrm{H} 2$ antagoinsts, PPI \\
Antibiotics & metronidazole, griseofluvin \\
Chemotherapies & Any \\
Musculoskeletal & colchicines, NSAIDs, \\
& penicillamine, methotrexate \\
\hline
\end{tabular}

Abbreviations: NSAIDs, non-steroidal anti-inflammatory drugs; PPI, proton pump inhibitors.

- Dementia/Alzheimer's disease

- Depression

- Anxiety

- Alcoholism

- Bereavement

\section{Social}

- Poverty

- Isolation

- Inability to shop, prepare and cook meals

All the diseases mentioned above are associated with higher rates of malnutrition in older people. Many older people do not have their own teeth $-59 \%$ aged 65 to 74 use dentures according to one survery. ${ }^{71}$ Poor dentition and ill-fitting dentures may limit the type and quantity of food they eat. Chewing problems are associated with a greater likelihood of poor health and decreased quality of life. ${ }^{72}$ Depression is common in older people and can present in $2 \%$ to $10 \%$ of the community. ${ }^{73}$ One of the most common presentations is loss of appetite and weight loss. It has been documented that $30 \%$ to $36 \%$ of weight loss seen in outpatients and the nursing home is due to depression. ${ }^{74}$ An inverse relationship between energy intake and cognition has been shown in hospital patients with dementia. ${ }^{75}$ Weight loss and changed behavior are associated with late stage disease. Fifty percent of patients with Alzheimer's cannot feed themselves 8 years after their diagnosis. ${ }^{76}$ Also olfactory changes occur in Alzheimer's which may affect food intake. ${ }^{77}$ Older people living on their own and socially isolated tend to eat less. These same people eat up to $50 \%$ more with company. ${ }^{78}$

\section{Nutrition}

\section{Macronutrients and micronutrients}

The recommended dietary allowance (RDA) for protein is $0.8 \mathrm{~g}$ protein $/ \mathrm{kg}$ body weight per day for adults regardless of age ${ }^{78}$ This is the minimum amount of protein intake required to avoid progressive loss of lean body mass. Evidence has 
revealed that protein intake greater than the RDA helps to improve muscle mass, strength and function in older people. Furthermore this intake can improve immune status, wound healing and blood pressure. ${ }^{79}$ Concerns about the detrimental affects of increased protein intake on bone health, renal function, neurological function and cardiovascular function are generally unfounded. It has been recommended that the RDA intake of $1.5 \mathrm{~g}$ protein $/ \mathrm{kg}$ body weight per day is a reasonable intake in older people to optimize protein intake in terms of health and function. ${ }^{80}$

Reduced intake and unbalanced diet predispose older people to vitamin and mineral deficiencies. Drugs can affect the absorption of vitamins, and can also interfere with hepatic metabolism, causing delayed elimination of vitamins. Smoking interferes with absorption of vitamins, particularly vitamin $\mathrm{C}$ and folic acid. Older people do not clear vitamin $\mathrm{A}$ well and are subsequently prone to hypervitaminosis.

Reduced vitamin D can result from reduced dietary consumption, and gastrointestinal and renal disease. Vitamin D deficiency leads to osteomalacia, rickets and myopathy. It is associated with reduced bone density, impaired mobility, increased risk of falls and probably an increased risk for developing type 1 diabetes, cardiovascular disease and rheumatoid arthritis. ${ }^{81}$ Dietary requirements in older people are higher due to reduced skin production, decreased exposure to sunlight and thinning of the skin.

Vitamin B12 deficiency occurs in $12 \%$ to $14 \%$ of community-dwelling in people $>60$ years of age and up to $25 \%$ of institutionalized older people. ${ }^{82}$ It can cause macrocytic anemia, subacute combined degeneration of the spinal cord, neuropathies, ataxia, glossitis and dementia. ${ }^{83}$ It also causes an increased level of homocystine, which increases risk of cardiovascular disease, ${ }^{84}$ and is associated with reduced bone density and increased hip fracture rate. ${ }^{85}$ In older people atrophic gastritis and pernicious anemia are the most common causes of vitamin B12 deficiency; less common causes are a strict vegetarian diet over a period of time (10 to 30 years) or inadequate absorption after gastrectomy or illeostomy.

Folate is present in orange juice, dark green leafy vegetables, peanuts, strawberries, dried beans and peas, and asparagus, among others. Four to $50 \%$ of older people have been reported with folate deficiency, with higher levels in those institutionalized. ${ }^{86}$ It causes macrocytic anemia and increased homocystine level, and is associated with increased risk of colorectal cancer, possibly cervical cancer, and cognitive impairment and depression. ${ }^{86}$ The main cause is due to diet insufficiency. Other causes are drugs (eg, methotrexate) and excess alcohol consumption.
Mineral requirements in old age do not change. Zinc, selenium, chromium, copper and manganese levels are unchanged with healthy aging.

\section{Fluid and electrolyte regulation}

Older people are more susceptible to develop problems with fluid and electrolyte balance due to physiological renal impairment and changes in thirst perception. Fluid deprivation and repletion studies comparing younger adults with the older population have demonstrated that despite physiological needs, older people do not consume adequate amounts of fluids to maintain ideal plasma electrolyte concentrations. ${ }^{87,88}$ This impaired fluid and electrolyte balance is due to several factors, including reduced glomerular filtration rate, reduced ability to concentrate urine, less efficient sodium-conserving capacity, reduced ability to excrete water load and altered thirst sensation. ${ }^{87,88}$ Fluid intake in older people can be further affected by physical disability and cognitive impairment. Adverse effects of drugs such as diuretics, either by altering thirst or prompting dieresis, cause dehydration.

\section{Nutritional therapy in older people}

Reduced intake due to medical, social and physiological factors should be addressed. For example patients with difficulty chewing should have dental and oral care checked and possibly be given mushy food. Patients with difficulty swallowing, eg, stroke patients, need speech and language therapy and possibly percutanous endoscopic gastrostomy (PEG) feeding. Patients with physical difficulties should have nursing assistance and those with low mood should have their medication reviewed and, if needed, started on appropriate treatment. Older people in isolation should have social services assistance and 'meals on wheels' to help improve food intake.

Older people in general have reduced oral intake. The main goal should be to help improve oral food intake. A study looking at hospital patients from different specialities demonstrated that $40 \%$ of food was wasted and that energy and protein intake was less than $80 \%$ of that recommended. ${ }^{89}$ Forty-two percent of older patients stated meal sizes were too large. Another study looked at older people receiving either normal or a reduced portion size fortified menu which provided $14 \%$ more energy than the normal menu. Intake was $25 \%$ higher on the fortified menu. ${ }^{90}$ A study using fortified menu demonstrated that between-meal snacks were also suitable to improve energy intake in older people in hospital. ${ }^{91}$ Modifying the dining environment in care homes has been shown to improve dietary intake. For example providing cafeteria style meals over a course of 3 weeks compared to traditional meal 
delivery on trays at one long-term home significantly increased energy intake. ${ }^{92}$ A 20-day trial at another care home showed that verbal cuing and individual physical guidance improved dietary intake by $29 \%$ to $56 \%{ }^{93}$ Food texture preferences were felt to be beyond the scope of this review article.

In patients with proven deficiencies of micronutrients, supplementation should be given. Calcium and vitamin D supplementation have been shown to reduce the incidence of hip fractures. ${ }^{94}$

Oral liquid energy-dense and high-quality protein supplements have been shown to increase energy and protein intake in critically ill patients. ${ }^{95}$ Supplements have also been shown to improve clinical and functional outcomes and reduce mortality rate. Enteral feeding is indicated if a patient is severely malnourished or if food cannot be taken orally due to medical illness, eg, stroke. In the short term, a nasogastric tube can be used and in the longer term PEG is indicated.

\section{Overnutrition in older people}

The prevalence of overweight (using standard BMI criteria) older people in Westernized countries is increasing. In 2000, $58 \%$ of US citizens aged $\geq 65$ years had a BMI of $\geq 25^{96}$ and the prevalence of obesity $(\mathrm{BMI}>30)$ in the US increased $36 \%$ from during 1991 to $2000 .{ }^{97}$ The relative risk of death in older people with high BMI is not as great as in younger people, but nevertheless is associated with a similar increased risk of mortality from conditions such as diabetes, hypertension and cardiovascular disease. Also older people with high BMI suffer from symptomatic osteoarthritis, increased rates of cataracts, mechanical urinary and bladder problems, and sleep apnea and other respiratory problems.

Although intentional weight loss by overweight older people is probably safe and beneficial, caution should be exercised in recommending weight loss to overweight older people on the basis of body weight alone. Methods of achieving weight loss in older adults are the same as in younger adults. ${ }^{99}$ Weight loss diets should be combined with an exercise program to preserve muscle mass, as dieting results in loss of muscle as well as fat, and older people already have reduced skeletal muscle mass. Weight loss drugs have not been extensively studied in older people, and there is the potential for drug side effects and interactions. Weight loss surgery appears to be safe and effective, albeit slightly less so than in younger adults, but little is known about the outcomes of such surgery in those aged $>65$ years. ${ }^{99}$

\section{Conclusion}

Older people are at an increased risk of inadequate diet and malnutrition, and the rise in the older population will put more patients at risk. Inadequate diet and malnutrition are associated with a decline in functional status, impaired muscle function, decreased bone mass, immune dysfunction, anemia, reduced cognitive function, poor wound healing, delay in recovering from surgery, and higher hospital and readmission rates and mortality.

Aging is associated with a decline in number of physiological functions that can affect nutritional status, including reduced lean body mass, changes in cytokine and hormonal levels, delayed gastric emptying, changes in fluid electrolyte regulation, and diminished sense of smell and taste. Pathological causes such as chronic illness, depression, medications and social isolation can all play a role in nutritional inadequacy. Screening is vital in identifying and monitoring patients. The MUST tool has been well validated and is easy to use. Management involves treating pathological causes such as poor dentition and optimizing the management of chronic diseases. Patients with physical or cognitive impairment require special care and attention. Oral liquid high-energy supplements or enteral feeding should be considered in high risk patients or in patients unable to meet daily requirements.

\section{Disclosure}

The authors declare no conflicts of interest.

\section{References}

1. Stratton RJ, Green CJ, Elia M. Disease Related Malnutrition: an Evidence Based Approach to Treatment. Oxford: CABI; 2003.

2. Office of National Statistics. Population trends. PT 118, table 1.4 (population age and sex) London: ONS; 2004.

3. Office of National Statistics. Living in Britain: results from the 2002 General Household Survey. London: ONS; 2004.

4. Morely JE. Anorexia of aging: physiological and pathological. Am J Clin Nutr. 1997;66:760-773.

5. Chapman IM. Nutritional disorders in the elderly. Med Clin North Am. 2006;90:887-907.

6. Saffrey MJ. Aging of the enteric nervous system. Mech Ageing Dev. 2004;125;266-271.

7. Cowen T, Johnson RJ, Soubeyre V, Santer RM. Restricted diet rescues rat enteric motor neurones from age related cell death. Gut. 2000;47:653-660.

8. Santer RM, Baker DM. Enteric neuron numbers and sizes in Auerbach's plexus in the small and large intestine of adults and aged rats. J Auton Nerv Syst. 1988;25;59-67.

9. Moore JG, Tweedy C, Christian PE, Datz FL. Effect of age on gastric emptying of liquid-solid meal in man. Dig Dis Sci. 1983;28;340-344.

10. Fich A, Camilleri M, Phillips SF. Effect of age on human gastric and small bowel motility. J Clin Gastroenterol. 1989;11;416-420.

11. Bitar Kn, Patel SB. Aging and the gastrointestinal smooth muscle. Mech Ageing Dev. 2004;125;907-910.

12. Elphick H, Elphick D, Sanders D. Small Bowel Overgrowth. An unrecognised cause of malnutrition in older adults. Geriatrics. 2006;61:21-25.

13. McEvoy A, Dutton J, James OF. Bacterial contamination of the small intestine is an important cause of occult malabsorption in the elderly. BMJ. 1983;287;789-793. 
14. Parlesak A, Klein, Schecher K, Bode Jc, Bode C. Prevalence of small bowel bacterial overgrowth and its association with nutrition intake in non hospitalized older adults. J Am Geriatr Soc. 2003;51;768-773.

15. Gullo L, Ventucci M, Naldoni P, Pezzilli R. Aging and exocrine pancreatic function. J Am Geriatr Soc. 1986;34:790-792.

16. Laugier R, Benard JP, Berthezene, Dupuy P. Changes in pancreatic exocrine secretion with age: pancreatic exocrine secretion does decrease in the elderly. Digestion. 1991;50:202-211.

17. Dreiling DA, Treibling AT, Koller M. The effect of age on human exocrine pancreatic secretion. Mt Sinai J Med. 1985;52:336-339.

18. Popper H. Aging and the liver. Prog Liver Dis. 1986;8:659-683.

19. Cao SX, Dhabbi JM, Mote PL, Spindler SR. Genomic proliferating of short term and long term effects in the liver of aging mice. Proc Natl Acad Sci U S A. 2001;98:10630-10635.

20. Aging and the intestine. World J Gastroenterol. 2006;12:7578-7584.

21. Marin K, Kirwood TB, Potten CS. Age changes in stem cells of murine small intestinal crypts. Exp Cell Res. 1988;241:316-323.

22. Hohn PR, Pascal RR, Kotler DP. Effect of aging of the rat intestinal mucosa. II. Morphological aspects of the aging of the small intestinal mucosa. Mech Ageing Dev. 1978;7:217-226.

23. Keelan M, Walker K, Thompson AB. Intestinal morphology, markers enzymes and lipid content of brush border membranes from rabbit jejunum and ileum: effect of aging. Mech Ageing Dev. 1985:49-68.

24. Wurtman JJ, Leiberman H, Tsay R, et al. Caloric and nutrient intake of elderly and young subjects measured under identical conditions. J Gerontol. 1988;43:B174-B180.

25. Villareal DT, Apovian CM, Kushner RF. Obesity in older adults: technical review and position statement of the American Society of Nutrition and NAASO. The Obesity Society. Am J Clin Nutr. 2005;82;923-924.

26. Wallace JI, Schwartz RS, LaCroix AZ, et al. Involuntary weight loss in older outpatients: incidence and clinical significance. J Am Geriatr Soc. 1995;43(4):329-337.

27. Newman AB, Arnold AM, Burke GL, et al. Cardiovascular disease and mortality in older adults with small abdominal aortic aneurysms detected by ultrasonography. The Cardiovascular Health Study. Ann Int Med. 2001;134:182-190.

28. Calle EF, Thun MJ, Petrelli JM, et al. Body mass index and mortality in a prospective cohort of US adults. $N$ Engl J Med. 1999;341:1097-1015.

29. Potter JF, Schafer DF, Bohi RL. In hospital mortality as a function of body mass index; an age dependant variable. J Gerontol. 1988;43. M59-M63.

30. Prentice AM, Jebb SA. Beyond body mass index. Obesity Rev 2001;2:141-147.

31. Cree MG, Newcomer BR, Katsonos CS, et al. Intramuscular and liver triglycerides are increased in the elderly. J Clin Endocrinol Metab. 2004;89:3864-3967.

32. Roubenoff R. The path physiology of wasting in the elderly. J Nutr 1999;121 Suppl 1:256-259S.

33. Yeh SS, Schuster MW. Geriatric cachexia: the role of cytokines Am J Clin Nutr. 1999;70:183-197.

34. Evans WJ. Exercise, nutrition and aging. Clin Geriatr Med. 1995;11: 725-734.

35. Roubenoff R. Sarcopenia and its implications for the elderly. Eur J Clin Nutr. 2000:54 Suppl 3:S40-S47.

36. Doty RL, Shaman P, Applebaum SL, et al. Smell identification ability: changes with age. Science. 1984;226:1441-1443.

37. Schiffman SS. Taste and smell losses in normal aging and disease. JAMA. 1997;278:1357-1362.

38. Mathey MF, Siebelink E, de Graff, et al. Flavour enhancement of food improves dietary intake and nutritional status of elderly nursing home residents. J Gerontol A Biol Sci Med Sci. 2001;56:M200-M2005.

39. Morley JE. Decreased food intake with aging. J Gerontol A Biol Sci Med Sci. 2001;56:81-88.

40. Roberts SB, Fuss P, Heyman MB, et al. Control of food intake in older men. JAMA. 1994;272:1601-1606.
41. Morton GJ, Cummings DE, Baskin DG, Barsh GS, Schwartz MW. Central nervous system control of food intake and body. Nature. 2006;443:289-295.

42. Strader AD, Woods SC. Gastrointestinal hormones and food intake. Gastroenterology. 2005;128:175-191.

43. Di Francesco V, Zamboni M, Dioli A, et al. Delayed postprandial gastric emptying and impaired gallbladder contraction together with elevated cholecystokinin and peptide YY serum levels sustain satiety and inhibit hunger in healthy elderly persons. J Gerontol A Biol Sci Med Sci. 2005;60:1581-1585.

44. Batterman RL, Cowley MA, Small CJ, et al. Gut hormone PYY physiologically inhibits food intake. Nature. 2002;418:620-653.

45. MacIntosch GC, Andrews JM, Jones KL, et al. Effects of age on concentrations of plasma cholecystokinin, glucagon-like peptide-1 and peptide YY and their relationship to appetite and pyloric motility. Am J Clin Nutr. 1999;69:999-1006.

46. Zamboni M, Zoico E, Fantin F, et al. Relation between leptin an the metabolic syndrome in elderly women. J Gerontol A Biol Sci Med Sci. 2004:59:396-400

47. Van der Lely AJ, Tschop M, Heiman ML, Ghigo E. Biological, physiological and pharmacological aspects of ghrelin. Endocr Rev. 2004;25:426-427.

48. Doucet E, St-Pierre S, Almeras N, et al. Quebec Family Study: Fasting insulin levels influence plasma leptin levels independently: evidence from both a cross sectional and an intervention study. J Clin Endocrinol Metab. 2000:85:4231-4237.

49. Murdolo G, Lucidi P, Di Loreto C, et al. Insulin is required for prandial gherlin suppression in humans. Diabetes. 2003:52:2923-2927.

50. Pirlich M, Lochs H. Nutrition in the elderly. Best Pract Res Clin Gastroenterol. 2001;15:869-884.

51. Omran ML, Morley JE. Assessment of protein energy malnutrition in older persons, part 1: history examination, body composition and screening tools. Nutrition. 2000;16:50-53.

52. Sullivan DH, Walls RC. The risk of life threatening complications in a select population of geriatric patients: the impact of nutritional status. J Am Coll Nutr. 1995;14:29-36.

53. Ellia M, editor. Screening for Malnutrition. A multidisciplinary Responsibility. Development and use of the 'Malnutrition Universal Screening Tool' ('MUST') for Adults. British Association of Parenteral and Enteral Nutrition; 2003.

54. Knodrup J, Allison SP, Ellia M, Vellas B, Plautg M. ESPEN guidelines for nutrition screening 2002. Clin Nutr. 2003;22:415-421.

55. Stratton RJ, Hackston A, Longmore D, et al. Malnutrition in hospital outpatients and inpatients: prevalence, concurrent validity and ease of use of the 'Malnutrition Universal Screening Tool' ('MUST') for adults. Br J Nutr. 2004:92:799-808.

56. Beck Am, Ovesen L, Osler M. The 'Mini Nutritional Assessment' (MNA) and the 'Determine Your Nutritional Health' Checklist (NSI Checklist) as predictors of morbidity and mortality in an elderly Danish population. Br J Nutr. 199;81:31-36.

57. Ek AC, Unosson M, Larsson J, et al. Interrater variability and validity in subjective nutritional assessment of elderly patients. Scand J Caring Sci. 1996:10:163-168.

58. Cena H, Madini N, Zaccardo A, Rondanelli, Roggi C. Nutritional assessment of elderly people. Minerva Gastroenterol Dietol. 2008;54:295-306.

59. WHO. Physical status: the use and interpretation of anthropometry. Report of a WHO Expert Committee. WHO Technical Report Series 854. Geneva: World Health Organization; 1995.

60. Stevens J, Cai J, Pumuk ER, Williamson DF, Thun MJ, Wood JL. The effect of age on the association between body mass index and mortality. N Engl J Med. 1998;338:1-7.

61. Hickson M, Frost G. A comparison of three methods for estimating height in the acutely ill elderly population. J Hum Nutr Diet. 2003;16:13-20.

62. WHO document. Measuring obesity - classification and description of anthropometric date. Nutrition Unit. EUR/ICP/NUT 125. Copenhagen: WHO Regional Office for Europe; 1989.

63. Allard JP, Aghdassi E, McArthur M, Mcgeer A, Simor A, Abdolell M. et al. Nutrition risk factors for the survival in elderly living in Canadian long term care facilities. J Am Geriatr Soc. 2004;59-65. 
64. Haboubi N, Haboubi H, Kennedy J. Obes Facts. 2009.

65. Suttmann U, Selber O, Boker K, et al. Incidence and prognostic value of malnutrition and wasting in human immunodeficiency virus-infected outpatients. Journal of AIDS and Human Retrovirology. 1995;8:239-246.

66. Pritchard C, Kyle Ug, Bracco D, et al. Reference value of fat free masses by bioelectrical impedance analysis in 3393 healthy subjects. Nutrition. 2000;16:245-254.

67. Alpers DH, Klein S. Approach to the patient requiring nutritional supplementation. In Yamada T, editor. Textbook of Gastroenterology, 4th edition. Baltimore: Lipponcott and Wilkins; 2003.

68. Jeejeebhoy KN, Baker JP, Wolman St, et al. Critical evaluation of the role of clinical assessment and body composition studies in patients with malnutrition and after total parenteral nutrition. Am J Clin Nutr. 1982;35:1117-1127.

69. Garibella SE, Sinclair AJ. Nutrition, aging and ill health. Br J Clin Nutr. 1998;80:7-23.

70. Azad N, Murphy J, Amos SS, Toppan J. Nutrition survey in an elderly population following admission to a tertiary care hospital. Can Med Assoc J. 1999;161:511-515.

71. Steele J. National Diet and Nutrition Survey: people aged 65 years and over, Vol 2. Report of the oral health survey. London. The Stationary Office; 1998.

72. Nakanishi N, Hino Y, Ida O, et al. Associations between self assessed matiscatory disability and health of community-residing elderly people. Community Dent Oral Epidemiol. 1999;27:366-371.

73. Evers MM, Marin DB. Mood disorders. Effective management of major depressive disorder in geriatric patients. Geriatrics. 2002;57:36-40.

74. Morely JE, Kraenzle D. Causes of weight loss in a community nursing home. J Am Geriatr Soc. 1994;42:583-585.

75. Incalzi Ra, Capparella O, Gemma A, et al. Inadequate caloric intake: a risk factor for mortality of geriatric patients in acute care hospital. Age Ageing. 1998;27:303-310.

76. Volicer L, Selzer B, Rheaume Y, et al. Progression of Alzheimer's disease. J Am Diet Assoc. 1989;89:392-396.

77. Gilbert PE, Pauk E, Barr PJ. Differences in olfactory and visual memory in patients with pathologically confirmed Alzheimer's disease and the Lewy body variant of Alzheimer's disease. Journal of the International Neurophysiologist Society. 2004:10;835-842.

78. Institute of Medicine. Dietary reference intakes for energy, carbohydrates, fibre, fat fatty acids, cholesterol, protein and amino acids. Washington DC. National Academy Press; 2005.

79. Wolfe RR, Miller LM, Miller KB. Optimal protein intake in the elderly. Clin Nutr. 2008;27:675-684.

80. Fukagawa N. Protein and amino acid metabolism and requirements in older persons. Clinic Geriatr. 1987.

81. Calvo MS, Whiting SJ, Barton CN. Vitamin D fortification in the United States and Canada: current status and data needs. Am J Clin Nutr. 2004;80 Suppl:1710S-1716S.
82. Krasinski SD, Russell RM, Samaloff IM, et al. Fundic atrophic gastritis in an elderly population: effect on haemoglobin and several serum nutritional indicators. J Am Geriatr Soc. 1986;34:800-806.

83. Abyad A. Prevalance of vitamin B12 deficiency among demented patients and cognitive recovery with colbalamin replacement. $J$ Nutr Health Aging. 2002;6:254-260.

84. Bonaa KH, Njolstad I, Ueland PM, et al. Homocystine lowering and cardiovascular event after myocardial infarction. $N$ Engl $J$ Med. 2006;354:1578-1588.

85. McLean RR, Jacques PF, Selhub J, et al. Homocystine as a predictive factor for hip fracture in older persons. $N$ Engl J Med. 2004;350: 2042-2049.

86. Ramersaud GC, Kauwell GP, Bailey LB. Folate a key to optimizing health and reducing disease risk in the elderly. J Am Coll Nutr. $2003 ; 22: 1-8$.

87. Drewenowski A, Warren Mears VA. Does aging change nutrition requirements? J Nutr Health Aging. 2001;5:70-74.

88. Rolls BJ, Phillips PA. Aging and disturbances of thirst and fluid balance. Nutr Rev. 1990;48:137-143.

89. Barton AD, Beigg CL, MacDonald IA, Allison SP. High food wastage and low nutritional intakes in hospital patients. Clin Nutr. 2000;19: 445-449.

90. Barton AD, Beigg CL, MacDonald IA, Allison SP. A recipe for improving food intakes in elderly hospitalised patients. Clin Nutr. 2000;9:451-454.

91. Gall MJ, Grible GK, Reeve NJ, Thomas SJ. Providing fortified meals and between meal snacks significantly increases energy intake of hospital patients. Proc Nutr Soc. 1998;57:94A.

92. Desai J, Winter A, Young KW, Greenwood CE. Changes in type of foodservice and dining room environment preferentially benefit institutionalised seniors with low body mass indexes. JAm Diet Assoc. 2007;107:814-815.

93. Simmons SF, Schnelle JF. Individualised feeding assistance care for nursing home residents;staffing requirements to implement two interventions. J Gerontol A Biol Sci Med Sci. 2004;509:M966-M973.

94. Chapuy MC, Arlot ME, Buoeuf F, et al. Vitamin D and calcium to prevent hip fractures in the elderly woman. $N$ Engl $J$ Med. 1992;327:1637-1642.

95. Bourdel-Marchasson I, Barateau M, Rondeau V, et al. A multicentre trial of oral nutritional supplementation in critically ill older patients. Nutrition. 2000;16:1-5.

96. Flegal KM, Caroll MD, Ogden CL, et al. Prevalence and trends in obesity among US adults 1999-2000. JAMA. 2002;288:1723-1727.

97. Mokdad AH, Bowman BA, Ford ES, et al. The continuing epidemics of obesity and diabetes in the United States. JAMA. 2001;286:1195-1200.

98. Heiat A, Vaccarino V, Krumholtz HM. An evidence-based assessment of federal guidelines for overweight and obesity as they apply to older persons. Arch Int Med. 2001;161:1194-1203.

99. Chapman IM. Obesity in old age. Obes Metab. 2008;36:97-106.
Clinical Interventions in Aging

\section{Publish your work in this journal}

Clinical Interventions in Aging is an international, peer-reviewed journal focusing on evidence-based reports on the value or lack thereof of treatments intended to prevent or delay the onset of maladaptive correlates of aging in human beings. This journal is indexed on PubMed Central, MedLine, the American Chemical Society's 'Chemical

\section{Dovepress}

Abstracts Service' (CAS), Scopus and the Elsevier Bibliographic databases. The manuscript management system is completely online and includes a very quick and fair peer-review system, which is all easy to use. Visit http://www.dovepress.com/testimonials.php to read real quotes from published authors. 